\title{
Preface: Hans-Jürg Kuhn and the German Primate Center
}

\author{
E. Fuchs and E. W. Heymann \\ German Primate Center, 37077 Göttingen, Germany \\ Correspondence to: E. Fuchs (efuchs@gwdg.de)
}

The history of the German Primate Center (DPZ) is inextricably connected with Hans-Jürg Kuhn. His work and engagement were crucial during the planning period of the institute. Later, as scientific and managing director (wissenschaftlich-technischer Geschäftsführer, 1977-1996) he developed the DPZ into a multi-disciplinary research institute and a competence and reference center for primatological research. His philosophy and vision of an open center for primatology continues until today. This special issue provides a brief overview of the first years of the DPZ and highlights developments initiated, stimulated and fostered by Hans-Jürg Kuhn.

The origination of the DPZ and Kuhn's role are reviewed in the contribution by Michael Schwibbe, who outlines the route from first ideas for a primate center in Germany in the early 1960s through Kuhn's DFG (the German Research Foundation) memorandum (Denkschrift) to the final establishment of the DPZ as a research and service institute.

The Department of Pathology and Veterinary Services was the first department that became functional after the foundation of the DPZ. Its history and achievements are described in the contribution by Manfred Brack, the first head of the department. The integration of the Department of Pathology and Veterinary Services with the Experimental Pathology Group and the further development of research in primate pathology are described in the contribution of FranzJosef Kaup.

One of the six proposed departments of the DFG memorandum was "Virology and Cell Culture". In 1983, the De- partment of Virology was established and for many years the work focused on studies on immunodeficiency viruses and prion disease in rhesus monkeys. In his contribution Walter Bodemer provides an overview and presents some important findings of the department's work.

For many years, Kuhn's own research interests focused on tree shrews, and he catalyzed the foundation of a tree shrew colony at DPZ. This activity is reflected by the contributions by Eberhard Fuchs describing the history of the tree shrew colony at the DPZ and presenting selected aspects of stress research with these animals followed by reviews of Wolfgang Knabe and Stefan Washausen on the development of the nervous system of Tupaia belangeri and by Irina Ruf, Stefan Janßen and Ulrich Zeller investigating the ontogeny and comparative anatomy of internal nasal structures of the macrosmatic order Scandentia.

While behavioural and ecological research was not part of the original plans for the DPZ, Kuhn facilitated behavioural studies at the center and fostered field studies in primate habitat countries. The development from the first DPZ field study in 1985/86 to the uniqueness of DPZ by running four field research sites is outlined in the contribution by Eckhard W. Heymann and Jörg U. Ganzhorn.

This special issue makes no claim to be complete; thus it cannot really do full justice to Hans-Jürg Kuhn's role and importance for the DPZ. Nevertheless, we hope that it provides readers with an idea of what would be missed if HansJürg Kuhn had not driven the many different developments. 